\title{
"TROCABAN EL TRABAJO EN FIESTA Y REGOCIJO". ACERCA DEL VALOR DEL TRABAJO EN LOS ANDES HISTÓRICOS Y CONTEMPORÁNEOS
}

\author{
“THEY TURNED LABOUR INTO FIESTA AND ENJOYMENT". \\ ON THE VALUE OF LABOUR IN THE HISTORIC \\ AND CONTEMPORARY ANDES
}

\author{
Olivia Harris ${ }^{1}$
}

\begin{abstract}
Fuentes tempranas del siglo XVI asocian la noción de trabajo en los Andes con la de regocijo mientras que en su gran mayoría tanto los españoles de la colonia como los antropólogos lo consideran bajo el prisma de la compulsión desvinculándolo de sus aspectos rituales. En general, las teorías del trabajo en Occidente marxista o no ligan el trabajo y la produccion a la enajenación.

La experiencia de trabajo de campo de la autora la lleva a considerar, sin embargo, que no existe en aymara una palabra genérica para designar el trabajo y que se considera en primera instancia para quién y para qué se trabaja y que los andinos valorizan no sólo el trabajo que realizan para fortalecer y confirmar sus propias redes sociales, sino más específicamente el trabajar para la comunidad de la cual forman parte.

Existe entonces una ética del trabajo que hace que esté considerado como una bendición en oposición a la manera judeo cristiana de considerarlo en el Occidente.
\end{abstract}

Palabras claves: trabajo fiesta, teorías del trabajo en Occidente/en los Andes.

Sixteenth century sources associate the notion of labour in the Andes with that of enjoyment, while most colonial Spaniards and modern anthropologists see it as obligatory, ignoring its ritual dimensions. Generally speaking, Western theorists of labour, whether Marxist or not, link labour and production with alienation. Drawing on her fieldwork experience, the author notes that there is no Aymara word for labour in general. More important is the purpose and beneficiary of labour. Andeans not only value labour aimed at strengthening their own social networks, but more specifically labour that benefits the community to which they belong. The Andean ethic of labour therefore leads it to be considered as a blessing, in opposition to Judaeo-Christian ways of considering it as a curse.

Key words: Labour, fiesta, European and Andean theories of labour.

Cuando redactaba su tesis sobre la organización económica del Estado Inca, Murra hizo algunas reflexiones sobre la fama, ampliamente difundida entre los cronistas del XVI, que tenían los Inca de ser enemigos del ocio; llegando a la conclusión de que probablemente los linajes reales compartiesen con otras castas de gobernantes a través del mundo la opinión de que sus súbditos eran holgazanes por naturaleza, y que era menester emprender obras cada vez más imponentes para mantenerlos activos (Murra 1978 [1956], cap. 5).

Parece que Murra no volvió directamente sobre este tema en sus investigaciones posteriores, pero en las conferencias que dictaba durante el curso de su vida solía insistir en el alto valor del trabajo en el mundo andino y la importancia del hecho de que los campesinos no tributaban al Tawantinsuyu sino mayormente en días de trabajo, lo que los españoles luego clasificarían como "servicios personales". En este ensayo quisiera proseguir el camino indicado por él, al presentar algunas hipótesis sobre el valor del trabajo y sus múltiples significados. En particular, la afirmación de Garcilaso de la Vega, citada en el título, suscita una duda acerca de la separación categórica entre el trabajo y la fiesta o regocijo, la cual es fundacional en el pensamiento occidental.

Los europeos que conocieron el Estado incaico se impresionaron del orden y de la obediencia con que los campesinos servían a sus autoridades, a diferencia de los holgazanes nativos del Caribe; y

\footnotetext{
$1 \quad$ Nota de los Editores: La edición final de este número nos impactó con la inesperada noticia de la muerte de Olivia, quien fue una de las primeras que estuvo dispuesta a participar y enviar los dos manuscritos que acá se publican (ver sentidos homenajes de Albó y Bubba 2009 y Bouysse-Cassagne y Platt 2009).
} 
algunos postulaban una evangelización previa para explicar por qué las costumbres en el Tawantinsuyu eran tan similares a las cristianas. Al respecto, encontramos diversas opiniones en las fuentes del XVI: ¿Cómo fue que el Estado incaico llegó a ser tan opulento, tan próspero, sino fue esclavizando a las poblaciones sujetas a él? ¿Qué mecanismos hicieron que los indios trabajasen tanto? ¿Cómo podían los españoles conseguir que trabajaran más todavía? ¿Cómo obligarlos a que entrasen a trabajar en los socavones mineros cuando la doctrina cristiana se oponía tajantemente al trabajo compulsivo?

\section{Una Poética Andina del Trabajo}

Garcilaso nos ha legado una imagen inolvidable de cómo los campesinos trabajaban en las tierras del Inca. Veamos la cita clásica:

Beneficiábanlas en común; iban a ellas y a las del Sol. Todos los indios generalmente, con grandísimo contento y regocijo, vestidos de las vestiduras y galas que para sus mejores fiestas tenían guardadas, llenas de chapería de oro y plata y con grandes plumajes en las cabezas. Cuando barbechaban-que entonces era el trabajo de mayor contento- decían muchos cantares que componían en loor de sus Incas; trocaban el trabajo en fiesta y regocijo (Garcilaso de la Vega 1943 [1609]: Lib.V, cap. 2).

Es normal descontar las afirmaciones de Garcilaso por ser demasiado románticas cuando insiste en lo idílico del sistema inca; pero por más que idealizaba el Tawantinsuyu al recordar su juventud en el Cusco, propongo que en este caso deberíamos tomar sus dichos al pie de la letra, entre otras razones porque encontramos padrones similares en otros textos del XVI y hasta en los trabajos comunales que se realizan en las comunidades campesinas en nuestros tiempos, y que estamos frente a una valoración del trabajo profundamente diferente a la que nos propone la mentalidad instrumental y utilitaria del pensamiento occidental.

La lengua griega antigua, de acuerdo al historiador Moses Finley, "incluía un vocabulario excepcionalmente extenso para designar a los esclavos, más que en cualquier otra lengua" (Finley 1973:98). En el aymara del XVI-XVII por el contrario encontramos abundantes vocablos para designar a diferentes aspectos del trabajo, hasta tal punto que me atrevo a designarlo como una poética andina del trabajo. El jesuita Bertonio traduce trabajo en castellano a un vocabulario aymara mucho más vasto:

trabajar en dos chacras en un mismo día
- ayratha
trabajar en la chacra sin alzar la cabeza -
yapu alekhattatha, hallakhchatha
trabajar con ahinco - cchamatatatha, tuli-
tatatha, meqquetatha, phutitathata
trabajar echando el bofe - thalatha, arasa
liuisitha
trabajar con diligencia como buen traba-
jador - kichisitha
trabajar como fuerte sin sentir el cansancio
- paraquenacatha, halanacatha
trabajar mucho en andar, o en moler quinoa
- thayllitha
trabajar todo el día entero - urujaatha
trabajador muy grande - añancuri, kutu,
kichisiri, hani pali
trabajo labor - iranacaña, locanacaña
trabajar mucho lo que apenas pudieran
dos - añancutha
trabajar en compañía de otros en hacer casa,
o chacra, o cosas semejantes - yanastha
el que acude de buena gana a los trabajos
comunes - yanasiri (Bertonio 1956 [1612]
(I):454; (II):21, 392).

Es probable que Bertonio colaborara estrechamente con hombres bilingües y que en algún momento les preguntara cómo traducir trabajo al aymara. Podemos imaginar su sorpresa y su interés al darse cuenta de la gran riqueza de vocablos relacionados con este concepto. Es de notar que en los ejemplos citados no se trata de diferentes categorías del trabajo, ni de metáforas, sino mayormente de diferentes aspectos de trabajar duro; y además cabe recalcar que el jesuita no supo igualar la gama de conceptos para el trabajo aymara con otra igual en el castellano.

Es bien conocido que en el sistema tributario inca la formación de cada grupo estaba íntimamente ligada a sus obligaciones laborales. En el sistema decimal, las tareas a cumplir para el Estado eran repartidas por el señor a cada nivel, apoyándose en los datos censales registrados en los kipu. El khipukamayuq calculaba lo que cada 
grupo debía contribuir -hasta el mínimo grupo de cinco hogares- no en cantidades de maíz, tubérculos o tejidos, sino en días de trabajo, sea para la agricultura, la construcción, las artesanías o en servicios de caminos (Murra 1978 [1956]; Platt et al. 2006). Suyu significa obligacion laboral ("la parte que uno, o muchos, toman de alguna obra para trabajar" Bertonio 1956 [1612] (II):331-2) y de esta manera los "cuatro suyus" (el Tawantinsuyu) constituyeron en efecto una gigantesca división de trabajo. Cabe notar en este caso que no se trata de un conjunto de distintas tareas, tal como Durkheim analizaba la solidaridad orgánica que se establece en base a una variedad de tareas diferentes y complementarias (Durkheim 1893), sino que de acuerdo con el concepto de suyu se reparten tareas fundamentalmente similares dentro de cada grupo.

La gran obra de Waman Puma también echa luz sobre el valor del trabajo en el Tawantinsuyu, entre otros ejemplos sobre las categorías censales bajo el Tawantinsuyu. Es notable que cada categoría -desde los viejos hasta los niños- era definida por su capacidad de trabajar y por las tareas asignadas a ella. De esta manera leemos que el oficio de los ancianos de más de ochenta años "sólo es para comer y dormir; los que pueden hacen guascas, soga y frazadas, apa, y han de guardar casas de los pobres y criaban conejos y patos". Cada categoría se define por el trabajo que realiza, hasta que los recién nacidos son clasificados como "sin provecho" o incluso "otro que le sirva" (Guaman Poma de Ayala 1987 [1615]:192-193, 204-207, 212-213, 224-227).

Muchos españoles de la época consideraban que la notable obediencia de los indios hacia sus señores constituía una especie de esclavitud. Un caso notable es aquel de Juan de Matienzo, Oidor de Charcas en La Plata (1561-1579), quien opinaba que:

toda su pretención [de los Incas] era procurar - por todas vías- que sus súbditos fuesen pobres, y no poseyesen cosa própia, haciéndolos continuamente trabajar sin premio alguno en obras mayores y más costosas que las de Egipto... Hacíanles también hacer acequias y calzadas más insignes y mayores que las que hicieron los romanos, y hacer en sierras y cuestas muy altas y llenas piedras y peñas, andenes de piedras para que pudiesen sembrar en ellos, subiendo tierra de los llanos para poder sembrar y más fertil: cosa increíble a los que no han visto. Todo para no dejar un punto ocioso... Eran más que esclavos: ni aun eran señores de sus mujeres e hijos, antes el Inga las daba a quien quería (de Matienzo 1967 [1567]:8).

De manera parecida, el minero Capoche demostraba su desdén personal hacia aquellos trabajadores en las minas de Potosí de cuyos esfuerzos él mismo aprovechaba cuando escribía:

se puede inferir cuán humildes son los indios y simples, pues teniendo causa para no oír ni ver la mina se quisieron ofrecer a la muerte antes que hacer falta a su amo (Capoche 1959 [1585]:158).

Otro aspecto de las costumbres laborales que resultó ser incomprensible a los españoles era su preferencia por el trabajo comunal, como vemos claramente en los escritos de Polo Ondegardo: "entre estos indios, [su] costumbre en este caso es antiquísima, de gobernarse y regirse por comunidades en todo". El mismo autor añade con una mezcla de admiración y exasperación:

Se ha de entender que si hay obra pública nueva a que les manden acudir a que distribuyan generalmente cien indios, entre todos lo hacen con menos pesadumbre que si después de distribuidos a cualquier repartimiento les manden uno solo, aunque le paguen doblado de jornal de lo que comunmente ganan; porque lo primero, como está dicho, acuden por su costumbre, porque nunca tuvieron tasa, y lo demás tienen por notable agravio, porque todo lo que sale fuera de la distribución general, no lo usaron (Polo Ondegardo 1990 [1571]:150, 178).

No sabemos todavía hasta qué punto las tierras de cada unidad doméstica fueron labradas por el conjunto de la comunidad bajo el Tawantinsuyu, pero las fuentes hacen recalcar la eficiencia del sistema inca de asignar el trabajo tributario a cada unidad social, cuyos dirigentes luego tomaron la responsabilidad de distribuirlo entre sub-grupos en escala menor. Cuando tantos ejemplos apuntan a lo 
mismo, no es de extrañar que Louis Baudin (1972 [1928]) identificara a los Inca como "el primer estado socialista" al compararlo con el sistema bolchevique, que para el historiador francés era la máxima ejemplificación del autoritarismo, la falta de libertad y de propiedad personal y la compulsión al trabajo.

No es raro que Baudin hiciese alusión a los estados totalitarios del siglo XX cuando analizaba la "alegría de trabajar", y lo que él consideraba como la falta de garantías sobre la libertad e intereses personales en el sistema inca. El tema de la alegría de trabajar (arbeitsfreude) también influyó mucho al desarrollo del nacionalismo alemán en los siglos XIX y XX y los ideólogos del nacionalismo pretendían que se lograba mediante una subordinación total a los intereses de la nación (Campbell 1989). Sin embargo, cabe notar algunas diferencias fundamentales con el papel del trabajo en el Tawantinsuyu: por una parte el Estado inca no promulgaba una idea totalizante de la sociedad tal como lo hicieron estos estados modernos, y por otra es probable que "los cantares en loor de sus Incas" aludidos por Garcilaso fuesen una manera a la vez de confirmar los derechos a la tierra y de dar de comer a las divinidades del subsuelo. Es decir, podemos suponer que la "alegría de trabajar" de los súbditos del Inca se compensara tanto por el Estado que reconocía ciertos derechos como en el plano religioso mediante el cual se aseguraba la buena voluntad de sus dioses.

Un ejemplo llamativo del regocijo con que los indios iban a trabajar nos ha legado Ramírez del Águila, párroco en la región potosina en la década de 1640. Al describir cómo los indios se preparaban para cumplir con la mita en Potosí nos cuenta que "cuando algun capitán sale a Potosí, es con acompañamiento de sus indios a usanza de guerra, con sus armas antiguas y galanes con sus plumas" (Ramírez del Águila 1978 [1639]:131). Esta descripción cobra más fuerza todavía porque en general este cura se oponía a la mita. Sin embargo, en medio de una denuncia en contra de la condición servil de los mitayos y los riesgos que implicaba para sus personas y su condición espiritual, de pronto nos cuenta que "puestos en el trabajo lo llevan con tanto gusto y risa como si estuvieran en fiestas" (Ramírez del Águila 1978 [1639]:116). Se puede detectar en tal afirmación la gran ambivalencia que sentía Ramírez del Águila cuando observaba algo que iba directamente en contra de su cultura y su profesión religiosa acerca del valor otorgado al trabajo minero por aquellos indios.

\section{El Trabajo Como Valor}

La alegría de trabajar en común se puede observar también en los tiempos actuales. Mis propias experiencias, en el curso de mis investigaciones antropológicas, han puesto de relieve el ambiente festivo de los trabajos comunales entre los campesinos del norte potosino ${ }^{1}$. Las formas del trabajo comunal en el campo andino han constituido un tema bien desarrollado entre los investigadores ${ }^{2}$. Para muchas comunidades andinas también son precisamente sus formas de trabajo comunal las que las hacen distintas de los demás campesinos y del mundo urbano. No es de sorprenderse que las nuevas generaciones de militantes aymara hacen hincapié en tales instituciones cuando intentan demostrar no solamente que son diferentes, sino más bien de una ética superior que los demás grupos sociales. En Bolivia uno de los organismos pioneros en el desarrollo del movimiento aymara tomó como título Minka -una forma de intercambio del trabajo (Albó 1987) y varios estudiosos simpatizantes con el movimiento han concordado que la ética aymara es superior a la occidental, por dar más importancia a los intereses colectivos en vez de los individuales (p.ej., Temple 1989).

En el norte de Potosí algunas de las formas del intercambio de trabajo son bilaterales. Si bien se representan como una ética de colaboración, y de valorizar la comunidad más que el individuo, en los hechos también cumplen una función pragmática de redistribuir la capacidad laboral en su totalidad entre las distintas unidades domésticas. Este es el caso, por ejemplo, cuando un hogar necesita una mano de obra mayor para preparar una fiesta (Harris 1987). Al mismo tiempo se realizan faenas a nivel de la comunidad entera, para las cuales cada hogar tiene la obligación de enviar a alguien para trabajar. Mediante la faena se construyen casas comunales, por ejemplo, o hacen servicio de caminos y, si bien cada participante trae consigo su propia merienda, al mismo tiempo se fomenta el ambiente festivo ${ }^{3}$.

Los trabajos comunales manifiestan un espíritu más festivo cuando un hogar particular que va a realizar trabajos agrícolas o construir una casa es el anfitrión. Cuando yo vivía en la región templada de los valles norpotosinos en la década de 1970, casi todo el ciclo agrícola se realizaba mediante trabajos comunales, llamados chuqu, en los cuales el ambiente era de fiesta ${ }^{4}$. Era mal visto en los valles realizar los trabajos agrícolas a solas y un aspecto 
notable de los chuqu es que solamente los hogares más prósperos se hacían cargo de organizar el trabajo comunal y sobre todo de preparar comidas y bebidas para todos los participantes. Los terrenos de las viudas y los ancianos eran trabajados por los participantes al finalizar el trabajo en las chacras del hogar anfitrión y antes de empezar la fiesta. La gente se vestía con su ropa más elegante para salir a trabajar y adornaban el yugo con ramas de molle.

La literatura científica sobre los trabajos agrícolas suele destacar la suciedad, el sudor y el dolor que los acompañan. En las culturas campesinas europeas indudablemente la ropa elegante se conservaba para los domingos, es decir, para los días precisamente en que la gente no trabajaba, sino que iba a la misa. De esta manera, en los trabajos comunales del chuqu norpotosino encontramos una combinación de trabajo y rito que pone en duda la separación categórica entre ambas actividades (ver también van Kessel 1980). Cuando asistí por primera vez a un chuqu en la década de 1970 me hacía recordar el texto de Garcilaso. Si bien faltaban el oro y la plata e igualmente estaban ausentes "los cantares" para el Inca, por otra parte no faltaban "grandes plumajes" en el sombrero de alguno que otro joven, el ambiente era festivo y todos los participantes lucían su mejor ropa. Cuando la gente me explicaba que era costumbre ayudar a las viudas y ancianos de esta manera, era casi como si estuvieran citando a Garcilaso, quien hace 400 años había apuntado que "también labraban por concejo... las tierras de las viudas húerfanos y pobres" (Garcilaso de la Vega Lib. V, cap. 2).

Los campesinos estaban perfectamente conscientes de que no era universal trabajar de esta manera y me acuerdo una vez cuando masticábamos la hoja de coca en un momento de descanso que alguien me preguntó si en Inkiltira se trabajaba así. Sin embargo, los laymi estaban convencidos de que un aspecto importante de su humanidad residía precisamente en su capacidad de cooperar y trabajar en común.

Lo que le daba importancia a los chuqu no era sólo el ambiente festivo, sino también el trabajo en sí. Como me decían en repetidas oportunidades, "acostumbramos ayudar uno a otro". Si bien en otras regiones andinas el ayudar en los trabajos agrícolas corresponde a un criterio de "reciprocidad directa demorada", los chuqu norpotosinos no se realizan en base a un cálculo estricto de créditos y deudas ${ }^{5}$. Es más bien con respecto a los objetos y productos que se prestan o donan que los laymi hacen cálculos más estrictos de reciprocidad. Este contraste quizás se debe a las diferentes ideas de las propiedades que están en juego. Los objetos y los productos se atribuyen a individuos y expresan las capacidades vitales, tanto de ellos mismos como de sus parientes. Pero la capacidad vital de una comunidad de hacer producir sus terrenos es una expresión del poder común y la relación con sus dioses que engendran la vida. Los ritos del ayllu y de cada comunidad ayudan a mantener un flujo continuo de energías entre las divinidades y los seres humanos. Un elemento importante de este proceso ritual lo constituyen los trabajos agrícolas, especialmente en su forma colectiva.

Es su compromiso con los trabajos comunales lo que distingue a la "gente verdadera" (jaqi) de los $q^{\prime}$ ara que viven en los pueblos y centros urbanos ${ }^{6}$. Si bien los campesinos reconocen que aquellos son también cristianos, consideran sin embargo que tienen una ética y una identidad distintas. Como lo han subrayado muchos antropólogos, los campesinos creen que los q'ara no saben trabajar o que son perezosos (ver Arguedas y Ortiz 1973; Gose 2001). Siendo este el caso, me sorprendí y hasta me escandalicé, cuando los laymis daban grandes cantidades de sus cosechas a los comerciantes que venían a buscarlos a sus chacras mientras las recogían, a cambio de algún regalo de poco valor, como por ejemplo una cajita de fósforos o unas naranjas. Cuando yo protestaba que esta clase de intercambio no era justo y que los de afuera del ayllu los estaban explotando, solían responder que los q'ara, por más que tengan un estatus social y económico más elevado, no saben trabajar; les tienen pena porque no tienen terreno propio y es por esta razón que sienten la obligación de ayudarlos. En años recientes Goudsmit también ha observado una generosidad -o quizás una ingenuidad- parecida por parte de los campesinos de la región, quienes siguen sirviendo y ayudando a las familias patronas y terratenientes, aun cuando formalmente se abolieron las relaciones de servidumbre ya hace varias décadas (Goudsmit 2006).

Cuando he intentado describir esta generosidad aparentemente espontánea a otros científicos muchas veces se me ha contestado que esta manera de comportarse es irracional, por estar en contra de la lógica económica. ¿Cómo es posible que los campesinos, siendo tan pobres según los criterios de la ONU, regalen su trabajo y sus productos casi gratis a la gente de un estatus social superior? 
Sin embargo, al recalcar esta falta de cálculos estrictamente económicos con respecto al trabajo agrícola y sus productos, no cabe caer en la ilusión de que entre los ayllus se encuentre una utopía socialista. Si por una parte ellos atribuyen un alto valor a los trabajos comunales, por otra existe mucho faccionalismo y conflicto sobre recursos (Albó 1975). Además, si bien los trabajos comunales constituyen un aspecto íntegro de la comunidad y de cumplir debidamente con las obligaciones, al mismo tiempo son considerados como una carga, que a veces se vuelve pesada. Sin embargo, cuando hoy en día los campesinos lamentan que sus vecinos ya no tienen tiempo para llevar a cabo los trabajos comunales porque han migrado a la ciudad o al exterior, se refieren sobre todo al bienestar colectivo que está disminuido por la falta de trabajos comunales (Calestani 2007) ${ }^{7}$.

Tampoco pretendo afirmar que los campesinos andinos trabajan más que en otras partes de acuerdo con alguna programación cultural. Son muchos los que afirmarían lo contrario; por ejemplo, cuando la Reforma Agraria de 1953 abolió las relaciones serviles en Bolivia, la productividad agrícola bajó notablemente porque los campesinos se dedicaban más tiempo al consumo y aumentaron notablemente los días de fiesta. Hasta hoy día es común escuchar a los patrones de antaño proclamar que a los campesinos les falta una mano dura para obligarlos a trabajar, y que en la ausencia del trabajo servil los campesinos se han vuelto perezosos. En el contexto de una ex hacienda en la sierra ecuatoriana, se ha propuesto que tal actitud se comparte por algunos de los mismos campesinos, sobre todo los mayores de edad, quienes antaño habían servido como huasipungueros (Lyons 2006).

Se trata, entonces, no de un ritmo excepcionalmente elevado del trabajo entre los comuneros, sino del valor positivo atribuido a éste. Tampoco pretendo que los campesinos no se quejen de su situación y simplemente aguantan los abusos y las injusticias; sin embargo, no se quejan del trabajo en sí, sino que mediante el trabajo buscan mantener relaciones de igualdad entre diferentes hogares y distintas comunidades y de compartir los frutos de sus esfuerzos con los de afuera de la comunidad.

Aparte del valor social atribuido al proceso laboral, el trabajo comunal puede servir como mecanismo para delinear los grupos sociales. Por ejemplo, en su importante investigación sobre Pacariqtambo en el sur del Perú, Gary Urton demostró que los trabajos comunales constituyen y hacen visibles a los diferentes ayllus que en su conjunto forman el pueblo (Urton 1992). En la vida cotidiana de Pacariqtambo no es fácil darse cuenta de la existencia de los ayllus, sino que sólo cuando se trata de llevar a cabo alguna obra colectiva para beneficiar a toda la comunidad -por ejemplo el refaccionar la tapia de la iglesia o sembrar una chacra con cebada en beneficio de la escuela- normalmente se divide el trabajo entre los ayllus en unidades llamadas chhiuta. Estos se reparten a nivel de la comunidad, así que el trabajo se distribuye en forma equitativa, tanto entre los ayllus como a cada individuo dentro del ayllu. De esta manera, cada comunidad se diferencia en sub-unidades, las cuales compiten entre sí para cumplir las mismas tareas. Como bien lo señala Urton, los chhiuta tienen una significación parecida a la del suyu que ya mencionamos y constituyen un claro ejemplo de las particularidades en la que se atribuye valor al hecho de trabajar en conjunto en las culturas andinas.

En otras regiones, las investigaciones antropólogicas han hecho resaltar más bien el contraste entre las clases sociales que se desprende del trabajo comunal. Por ejemplo, en su estudio de Huaquirca (otro pueblo en el sur del Perú) Peter Gose analiza no tanto las relaciones entre los diferentes ayllus, sino más bien aquellas entre comuneros y "notables". Los trabajos colectivos, llamados ayni en aquella región, expresan una ética igualitaria que constituye la base de la vida comunal, a diferencia del grupo de "notables" quienes se niegan a colaborar en los ayni aun cuando cumplen otras tareas agrícolas (Gose 2001).

Tanto Urton como Gose indican que los trabajos comunales son imprescindibles para mantener los derechos a la tierra. He aquí un ejemplo en que el hecho de colaborar con algun trabajo comunal en sí constituye el derecho a la tierra. En la década de 1970 tuve la oportunidad de participar en el barbecho de un campo grande en el lindero entre Laymi y Aymaya a finales de la estación de lluvias. Salimos casi toda la estancia a trabajar juntos y de esta manera se proclamó la propiedad colectiva sobre el terreno para declarar el derecho de sembrarla al llegar la primavera. Después del barbecho, allí mismo la comunidad asignó por consenso chacras particulares no a todos los participantes, sino a las unidades domésticas a las cuales les faltaba terreno suficiente y de esta manera se lograba una distribución más equitativa del terreno dentro de la comunidad. 
En cuanto al trabajo realizado por migrantes fuera del ámbito de la comunidad, en general tuvo como objeto el ganar dinero para las necesidades individuales o del hogar. Sin embargo, el caso de la minería corresponde estrechamente a la ética comunal que hemos venido delineando. En las galerías y socavones los mineros crean su propia comunidad, mascando hojas de coca y ofreciendo ch'allas antes de emprender el trabajo. Tal como lo ha demostrado Pascale Absi en su estudio sobre la mina de Potosí, los mineros entran en una relación recíproca con las divinidades de la mina mediante las ofrendas colectivas, que al mismo tiempo sirven para constituir los equipos de trabajo que extraen los minerales y militan en los sindicatos y cooperativas. Es el mismo trabajo minero lo que ayuda a mantener y activar las fuerzas que animan al mundo (Absi 2005).

En su mayoría, las teorías sobre el valor se enfocan en los productos del trabajo, o sea, en la objetivación del trabajo. Sin embargo, en los ejemplos arriba citados es notable que es el trabajo mismo que expresa el valor y no sólo sus productos. Sin duda, la importancia del trabajo se desprende en parte del medio ambiente; la agricultura altoandina tanto como la minería son actividades riesgosas cuyos resultados son difíciles de anticipar. Sin embargo, sería erróneo explicar los valores atribuidos al trabajo como tan sólo un efecto de factores ecológicos, puesto que constituyen un elemento íntegro de los derechos a la tierra y la constitución de grupos sociales y a la vez contribuyen a mantener la subordinación de los campesinos frente a los q'ara de los pueblos y centros urbanos. El dar de comer tiene un valor trascendental en la región andina y mediante los trabajos comunales y las comidas festivas que los acompañan, los grupos sociales se manifiestan y se realizan. Al mismo tiempo, ofrecen comida a la tierra y los dioses del subsuelo, quienes a su vez les proveen comida ${ }^{8}$.

\section{Los Significados del Trabajo}

En las comunidades norpotosinas, al saludarse en el camino, es normal preguntar "¿qué estás haciendo?" o "¿adónde vas?", y normalmente la respuesta adecuada indica solamente el lugar adonde uno está yendo (p.ej., la chacra, el cerro, el río, la casa) y en cada caso es claro por la ubicación espacial la gama de actividades que uno va a desempeñar. Cada lugar está asociado con algún oficio -ir al cerro significa cuidar los ganados e ir al río significa lavar la ropa-, pero al responder normalmente indicando sólo un espacio la gente también incluye implícitamente otras actividades: el platicar, coquetear, cantar o hilar.

Sin embargo, algunas actividades se señalan de manera más precisa; y el barbecho es una de las principales de ellas. Este trabajo se realiza con una yunta de toros o de bueyes a finales de la estación de lluvias, para luego sembrar en septiembre, y es la actividad varonil por excelencia, por requerir una fuerza física excepcional. Las mujeres no barbechan, aunque a veces una mujer puede conducir el arado durante la siembra cuando la tierra es menos dura. De tal manera, cuando yo preguntaba a las mujeres qué es lo que más admiraban cuando buscaban un marido, me solían contestar "uno que sabe barbechar bien”. Quizás tal respuesta parezca obvia, por ser la producción agrícola el sustento principal de sus vidas; y además por la muy reconocida analogía entre el arar y el acto sexual. Cuando planteaba a los hombres "¿qué es lo que buscan y admiran en una mujer?" muchas veces contestaban diciendo que una mujer excelente es aquella que sabe cocinar bien y llevar una merienda riquísima a su marido mientras realiza el barbecho en la chacra ${ }^{9}$.

La uniformidad de las respuestas indica que esta división del trabajo entre marido y mujer representa en cierta forma la economía hogareña: es el hombre quien maneja el arado y la mujer es quien da de comer. Evidentemente esta división del trabajo es al mismo tiempo un acto de seducción, metafórico si no actual. Cabe señalar al respecto que cuando alaban la energía humana emplean la palabra wapu, tanto para el trabajo masculino como el femenino. Si bien el vocablo guapo del castellano refiere en primer lugar a la apariencia física, parece que una connotación sexual se expresa en aymara más bien con referencia al ánimo para trabajar ${ }^{10}$. Los que son tildados de perezosos, sean mujeres u hombres, difícilmente encontrarán una pareja.

Al mismo tiempo el barbechar es duro (ch'ama), y quizás es la capacidad de resistir la que más se estima, y que propiamente define al ser humano. Ch'ama significa a la vez la capacidad de aguantar de la persona, y la resistencia física que experimentan, por ejemplo en la dureza de la tierra durante el primer barbecho. En los ritos de la siembra para que la tierra produzca bien los jóvenes a veces imitan la yunta de toros, poniéndose el yugo y corriendo a través de las chacras; y siempre cuando se emborrachan 
durante las fiestas los varones suelen rugir como toros y gritar que son los toros de la comunidad. De tal manera la fuerza del toro representa la esencia del trabajo masculino.

Los toros, al parecer, ocupan un espacio semántico similar al amaru o katari -la serpiente felino de la mitología andina-, la que se asociaba con los aguaceros y los ríos caudalosos del verano (Harris 2000; Zuidema 1989). Los hombres se vuelven toros durante los rituales, cuando barbechan y cuando entran al combate; y la fuerza de los toros representa la potencia de los cerros, fuente de todas las fuerzas meteorológicas que sustentan la vida, pero que a la vez son capaces de destruirla. El barbecho está estrechamente vinculado con el poder de los antepasados que hace que la tierra produzca. No es casual que Garcilaso al respecto comenta que el barbecho en tiempos incaicos era "el trabajo de mayor contento" y tampoco es casual que el vocablo tarwajaña se refiere al barbecho en el aymara de la región y no al trabajo en general.

Si bien el acto de la mujer que complementa al barbecho es aquel de guisar bien, no se considera como difícil (ch'ama) preparar la comida en el sentido de exigir resistencia física. Más bien es el parto y el criar a los hijos que las mujeres suelen clasificar como ch'ama $^{11}$. En los Andes el parto se asocia con el dolor y la enfermedad, un desequilibrio en el funcionamiento normal del cuerpo, o a veces se entiende mediante la metáfora de la guerra (Arnold y Yapita 1999; Platt 2001). En nuestros días, además, las campesinas se quejan de que es ch'ama tener tantos hijos como tienen ahora, en comparación con tiempos anteriores cuando criaban menos (Arnold y Yapita 1996).

Es normal que no exista un término genérico que se refiere al trabajo como categoría abstracta en las economías no capitalistas, y éste es el caso también en el aymara, aunque existe un vocablo que refiere a los trabajos agrícolas -irnaqaña- y otro general para "hacer" -luraña-que significa también obrar, fabricar, crear, ejecutar (p.ej., el cultivar la chacra es yap luraña). Una de las actividades fundamentales que se incluye en esta clasificación de "hacer" o "fabricar" (luraña) es el tejer. Esto se entiende como un acto paradigmático de la creación, y sirve como metáfora de otras diferentes actividades ${ }^{12}$. El tejer hace atractiva a la tejedora. En el pasado, todos los jóvenes solían esforzarse para fabricar ropa nueva. Al lucir la nueva moda en las fiestas demostraban su calidad de $w a p u$, y proclamaban públicamente que eran capaces de animar a sus próximos -su pareja, pero sobre todo a sus hermanos del otro género- de ayudarlos a vestir bien, el deseo de ser wapu y de emplear sus energías de manera creativa.

Concretamente, el trabajo no se puede entender sin tomar en cuenta para quién, y para qué, va a servir: se siembra la chacra "para comer", o quizás "para la fiesta" si la unidad doméstica va a ser alférez; o un/a joven puede cultivar una chacra "para dinero" si necesitan comprar algún adorno o ropa. De igual manera, las actividades de hilar y tejer demostraban claramente la red de relaciones sociales y de parentesco del tejedor, porque si bien una parte de sus labores tenía por objeto el proveer las necesidades del hogar otra parte iba destinada a los "hermanos" del sexo opuesto. Los que se llamaban "hermanos" hilaban y tejían uno para otro -mujer para hombre, hombre para mujer-durante toda la vida, y así demostraban el cariño que sentían. Para los laymi, la manera en que circulan los productos depende estrechamente de para quién y cómo fueron creados (Harris 1987). Es mediante los trabajos productivos que los seres humanos se forman a sí mismos y a los demás para quienes trabajan, o con quienes comparten los frutos de su trabajo (ver también Canessa 1998).

No es sorprendente que los antropólogos subrayen el alto valor atribuido a la energía humana, a la creatividad y a la capacidad de formar y expandir las relaciones sociales mediante el trabajo. Sin embargo, este valor es notable en la región andina por dos razones específicas: una porque los campesinos constituyen la base de una estructura social profundamente desigual, en la que han sido severamente explotados en muchos períodos históricos; y la otra porque valorizan no sólo el trabajo que realizan para fortalecer y confirmar sus propias redes sociales, sino más específicamente el trabajar para la comunidad de la cual forman parte ${ }^{13}$. En las teorías antropológicas, estos aspectos no han sido suficientemente debatidos y suscitan problemas interesantes de interpretación.

\section{El Espectro de la Compulsión}

Esta valoración positiva del trabajo es aún más notable si consideramos la frecuencia con que los científicos pretenden que el hacer trabajar a la gente siempre requiere un elemento de coerción. Como lo hemos visto, los españoles del XVI que intentaban igualar $-\mathrm{o}$ trascender- el monto de tributos 
alcanzado por los Inca despreciaban la manera de trabajar de los indios. Para Matienzo y Capoche, lo que los ofendía fue que los indios estuvieran sujetos a la voluntad de sus gobernadores y que por lo tanto fueran serviles y no libres. Polo Ondegardo, por su parte, denunciaba la falta de racionalidad cuando los indios insistían en el trabajo comunal aun cuando no daba beneficio.

Sea cual sea, estos comentarios pretenden que los indios debieran ser individuos desprovistos de cualquier relación social cuando entran a trabajar ${ }^{14}$ y este padrón de abstraer el trabajo de su contexto social se volvería fundamental en la economía política en siglos posteriores. Por ejemplo, Adam Smith identifica al trabajo productivo -abstraído de cualquier contexto social- como la fuente principal de la riqueza y Marx desarrolla esta idea en su teoría laboral del valor, basado en un concepto abstracto de la fuerza del trabajo, separada de la particularidad de cualquier trabajador individual (ver Arendt 1999).

En efecto, los conceptos marxistas del trabajo abstracto y la teoría laboral del valor se refieren en primer lugar a las economías capitalistas, con el fin de explicar el mecanismo a través del cual el trabajador fue enajenado del producto de su trabajo y por lo tanto explotado por los propietarios de los medios de producción ${ }^{15}$. Sin embargo, los antropólogos han aplicado estas abstracciones también a otros contextos donde no prevalecen los mecanismos capitalistas de extracción de plusvalía, por ejemplo para calcular el valor de un producto en base al tiempo laboral necesario para producirlo ${ }^{16}$. Al ser así, el trabajo se vuelve un objeto de análisis aislado de las relaciones sociales y la vida cotidiana, aunque en realidad restando el sistema capitalista clásico, y quizás los sistemas esclavistas, esta clase de abstracción es dificil de sostener.

La influencia del marxismo se hace sentir especialmente en los estudios sobre la explotación en distintos contextos sociales e históricos. Para las comunidades andinas de nuestros tiempos son varios los que han argumentado que las ideologías de reciprocidad y de cooperación cumplen el papel de encubrir una realidad social de desigualdad y de explotación (p.ej., Painter 1991:98; Sánchez 1982). De igual manera, Godelier ha afirmado que el Estado Inca se apoderó de sistemas anteriores de reciprocidad y de trabajos comunales para inaugurar nuevas relaciones de producción y ocultar la opresión y dominación subyacentes (Godelier 1977:68).
Sin embargo, estas aproximaciones pretenden que los valores sociales, que se desarrollaron a base de relaciones sociales de igualdad en el pasado, se mantienen por una especie de inercia y que los campesinos, siendo explotados por métodos indirectos, no son capaces de reconocerlo ${ }^{17}$.

Estos ejemplos coinciden con las teorías generales de la evolución social que muchas veces privilegian la explotación y la enajenación como mecanismos de cambio, y como tal implican que la desigualdad social es siempre resultado de una fuerza coercitiva. Si no, ¿cómo explicar que la gente llegase a renunciar a su libertad para subordinarse a otro?

No cabe duda que en muchos casos la compulsión es verdadera, por ejemplo en casos de la conquista o de la esclavitud en que la tierra y otros medios de producción están monopolizados por una minoría. Sin embargo, aun cuando no se explicitan los efectos de la compulsión, muchas veces contribuyen implícitamente al argumento. Tal es el caso del famoso texto de Sahlins de 1976 sobre La Economía de la Edad de Piedra, en el cual su teoría aparentemente benigna sobre las diferentes etapas de la evolución social, en realidad se respalda por una idea implícita de compulsión. De acuerdo con Sahlins, la producción aumenta junto con el aumento de la autoridad social y sin este mecanismo la gente no suele trabajar bien ni generar un excedente. Es inolvidable su imagen de "la sociedad opulenta primitiva" en que los recolectores y cazadores se dedicaban a una vida regalada. Aquellos agricultores que se sustentaban mediante "el modo de producción doméstico", que sucedió a la recolección en su esquema evolucionista, se dedicaban de igual manera al ocio, al placer, a las visitas y ceremonias. No se explicita cómo opera el poder señorial y hasta qué punto se descansa sobre las relaciones coercitivas, sino que más bien afirma que "la categoría indígena para denominar a la explotación es la reciprocidad". Sin embargo, no es difícil concluir cuando consideramos la estructura global de sus argumentos, que subyace a ellos una historia de los orígenes del trabajo penoso y de la obligación y que éstos son producto de la compulsión y una pérdida de libertad. De igual manera, como se ha visto, Murra planteaba en su tesis de 1956 una relación coercitiva para explicar por qué los campesinos andinos trabajaban tanto, y tan duro, para sus gobernantes.

Con el eclipse del marxismo los antropólogos dejaron los temas del trabajo y la producción para 
centrarse más bien en los mismos productos -las "cosas"- en la definición de Appadurai (1991). Este cambio de perspectiva se conjugó con el alejamiento en la economía política global del productivismo y el giro hacia una filosofía neoliberal, en otras palabras, se produjo un movimiento desde el trabajo mismo hacia el postfordismo y el consumo. Al mismo tiempo, otros investigadores se dedicaban a producir una etnografía matizada del trabajo que privilegiaba las experiencias vividas de los trabajadores y las formas en que valorizan sus propias actividades, en parte para compensar los defectos de un marxismo demasiado abstracto.

No cabe duda que los mismos trabajadores manuales siempre han acostumbrado valorizar sus propios esfuerzos y de promulgar el respeto hacia el trabajo (ver Thompson 1989). De esta manera los etnógrafos han demostrado que hasta los que cumplen los trabajos más despreciados suelen mantener su autoestima y procuran disfrutar de su empleo y a su vez desprecian a los que gozan de un rango social superior.

\section{Trabajo como Castigo, Trabajo como Bendición}

En este ensayo me he valido de un contraste quizás simplista entre los valores occidentales acerca del trabajo y aquellos de las culturas andinas. Cabe reconocer que existen en las tradiciones occidentales algunas corrientes que valorizan $-\mathrm{y}$ hasta sobrevalorizan- el trabajo manual en sí, como es el caso de los movimientos obreros (Thompson 1989), o de los estados totalitarios tales como los nazis o los bolcheviques. Sin embargo, en las fuentes fundacionales de la cultura occidental, tales como los filósofos griegos y la Biblia, el trabajo parece ser más bien una forma de castigo.

Para los griegos antiguos, el trabajo era penoso en sí (ponos-Vernant 1965:16-36). Aristóteles escribe en La Política que "aquellos que van a ser ciudadanos no pueden ser trabajadores del agro, porque necesitan tiempo libre para llegar a ser virtuosos y para desempeñar las funciones de un ciudadano" (Aristóteles 1874:1329a, 1). La única manera de dominar la necesidad fue mediante el empleo de esclavos y éstos no eran plenamente humanos justamente porque eran sujetos a la necesidad en vez de dominarla. De igual manera, los campesinos eran serviles porque estaban sujetos a la necesidad (Arendt 1999). En cuanto a la artesanía, si bien no era en sí un oficio degradante, también era considerada vil porque necesariamente implicaba vínculos de dependencia, puesto que los artesanos no consumen sus propios productos (Mossé 1969:27-29). Platón consideraba que el trabajo estaba desvinculado de cualquier valor humano, hasta tal punto que representaba la antítesis de la condición humana (Vernant 1965:12) ${ }^{18}$.

La tradición filosófica de los griegos valoriza sobre todo la búsqueda de la libertad y consideraba que, siendo aquella la fundación de la existencia humana, la única razón para trabajar es la necesidad. Según pareciera, los orígenes de la necesidad se encuentran más allá del mismo trabajador, y por tanto se recurre a la imagen de la esclavitud para captar lo esencial del trabajo manual. Una actitud parecida a ésta se puede detectar en los escritos de los Padres de la Iglesia temprana; por ejemplo, San Agustín consideraba que la máxima expresión de los valores humanos era la vida contemplativa. $\mathrm{Si}$ bien algunos filósofos cristianos alababan el trabajo, la razón era por ser la mejor manera de expiar los pecados y de evitar la tentación y no por ser un bien en sí (Le Goff 1980). Cabe notar que no sólo los Padres de la Iglesia sino también los filósofos griegos tuvieron un fuerte impacto sobre el pensamiento de los españoles cultos del XVI.

En la tradición bíblica el trabajo penoso fue consecuencia del Pecado Original. Tal como nos cuenta el mito del Génesis, la sentencia divina hacia Adán por su pecado fue maldecir a la tierra y condenarlo al dolor y sudor para poder sustentarse de ella, mientras que a Eva se la castigó con el dolor del parto y una subordinación eterna al hombre (Génesis 3:16-18). No es de sorprenderse que, según aquel mito, Dios obrase una separación nítida entre los días de trabajo y de descanso. Vale notar al respecto que hasta en nuestros días se mantiene la prohibición en contra del trabajo en los días de guarda en las comunidades norpotosinas, una prohibición que se remonta a estas tradiciones hebreas.

El mito del Génesis tal como lo cuentan los campesinos del norte de Potosí es notable por el valor positivo atribuido al trabajo. Según el mito, en la época previa a la cristiana no había sol, sino solamente la luna, y la gente de aquel entonces no trabajaba sino que todas sus necesidades -la comida, la bebida y hasta los vestidos- crecían milagrosamente de por sí. Fue cuando Dios apareció con la salida del sol que se inauguró la edad cristiana en que vivimos. Fue el Dios cristiano quien otorgó a la 
nueva gente los materiales para trabajar y para vivir -los "tres milagros" de los cultivos, los ganados y los minerales- y cuando los laymi se identifican como buenos trabajadores es por ser cristianos y haber recibido estos dones divinos. De tal manera, es claro que en el Génesis andino el trabajo, lejos de ser un castigo, se entiende como una bendición $\mathrm{y}$ una fuente de bienestar.

Quizás la existencia de una valoración tan negativa del trabajo en las ideas occidentales se deba al predominio de la esclavitud en el mundo antiguo. En el caso de Grecia antigua ya hemos comentado la importancia que tenían los esclavos para que los ciudadanos no tuvieran que envilecerse con trabajos manuales, y para Roma antigua es consabido el tema de la esclavitud. En el caso de los hebreos antiguos también, cabe notar que habían sufrido los efectos de la esclavitud y que mantenían vivas las tradiciones de su liberación, primero huyendo de Egipto y luego de Babilonia, a tal punto que en efecto se puede leer la Biblia como una larga historia de liberación de la esclavitud (Yerushalmi 1982). Si bien no podemos saber con exactitud cuándo se redactó en forma escrita el libro del Génesis, es muy probable que ocurriera durante, o después, del retorno de los israelitas de Babilonia, es decir, después de una segunda experiencia histórica de esclavitud. De esta manera, vemos que la polaridad entre la libertad y la compulsión juega un papel constitutivo en las ideas occidentales acerda del trabajo; y que cualquier forma de compulsión se puede interpretar como una condición servil porque representa una limitación a la libertad personal. Por consiguiente, podemos plantear como hipótesis, tal como lo afirmaba Aristóteles, que en la tradición occidental el trabajo en sí es antitético al pleno ejercicio de la libertad.

De modo parecido, los comentarios españoles del siglo XVI sobre la manera en que los campesinos andinos entraban a trabajar están fundados sobre un contraste tajante entre la libertad y la esclavitud. Por no percibir en la condición de los campesinos tributarios una libertad completa, estaban dispuestos a concluir que era servil. Este juicio seguramente influyó a algunos investigadores modernos que han planteado que el sistema incaico fue esclavista (p.ej., Choy 1962). Sin embargo, los trabajos de Murra han puesto de relieve la notable ausencia de esclavos en la sociedad incaica. Si bien Garci Diez, Visitador de los Lupaqa, quiso "liberar" a los "criados y criadas de servicio" de los señores (es decir, sus yana), la Visita de Chucuito no rinde ninguna evidencia de que aquellos yana se sintieran bajo una compulsión especial, ni que manifestaran un estatus inferior (Murra 2004).

Es de notar que Durkheim, el gran sociólogo francés, no incluyó en su análisis de la solidaridad mecánica los efectos de los trabajos comunales y tampoco mencionó que la "efervescencia colectiva", que resultaba de la práctica de los ritos en la mentalidad de los participantes, podría también producirse en el trabajo, sino que más bien seguía la ortodoxia judeo-cristiana en mantener una separación absoluta entre el rito y el trabajo (Durkheim 1893, 1912). Sin embargo, si el trabajar en las culturas andinas se lo considera no como un castigo sino una bendición y si los trabajos comunales parecen "fiesta y regocijo", tal como nos cuenta Garcilaso, podríamos plantear más bien que se trata de una práctica no desligada de los ritos religiosos.

\section{Referencias Citadas}

\footnotetext{
Absi, P.

2005 Los Ministros del Diablo. El Trabajo y sus Representaciones en las Minas de Potosí, Bolivia. IRD, IFEA y PIEB, Lima y La Paz. Alberti, G. y E. Mayer, editores

1974 Reciprocidad e Intercambio en los Andes Peruanos. Instituto de Estudios Peruanos, Lima.

Albó, X.

1975 La paradoja aymara: solidaridad y faccionalismo. Cuadernos de Investigación 8. CIPCA, La Paz.

1987 From MNRistas to Kataristas to Katari. En Resistance, Rebellion and Consciousness in the Andean Peasant World, editado por S. Stern, pp. 379-419. University of Wisconsin Press, Madison.
}

Appadurai, A., compilador

1991 La Vida Social de las Cosas: Perspectivas Culturales de las Mercancías. Editorial Grijalbo, México D.F.

Arendt, $\mathrm{H}$.

1999 La Condición Humana. Círculo de Lectores, Barcelona.

Arguedas, J.M. y A. Ortiz

1973 La posesión de la tierra, los mitos prehispánicos y la visión del universo en la población monolingüe quechua. En Ideología Mesiánica del Mundo Andino, editado por J. Ossio, pp. 217-36. Ignacio Prado Pastor, Lima.

Aristóteles

1874 Política. Medina y Navarro Editores, Madrid. 
Arnold, D.y J. de D. Yapita

1999 Vocabulario Aymara del Parto y de la Vida Reproductiva de la Mujer. Instituto de Lengua y Cultura Aymara/Family Health Internacional, La Paz.

1996 Los caminos de género en Qaqachaka: saberes femeninos y discursos textuales alternativos en los Andes. En Ser Mujer Indígena, Chola o Birlocha en la Bolivia Postcolonial de los años 90, editado S. Rivera Cusicanqui, pp. 303-392. Ministerio de Desarrollo Humano, La Paz.

Baudin, L.

1972 [1928] El Imperio Socialista de los Incas. Ediciones Rodas, Madrid.

Bertonio, L.

1956 [1612] Vocabulario de la Lengua Aymara. Universidad Mayor de San Andrés, La Paz.

Calestani, M.

2008 Creating our Own Well-being: Local Perspectives and Cultural Constructions in the Bolivian Altiplano. Tesis doctoral en Antropología, Universidad de Londres.

Campbell, J.

1989 Joy in Work, German Work. The National Debate 18001945. Princeton University Press, Princeton.

Canessa, A.

1998 Procreation, personhood and ethnic difference in Highland Bolivia. Ethnos 63(2):227-247.

Capoche, L.

1959 [1585] Relación de la Villa Imperial de Potosí. Biblioteca de Autores Españoles CXXII, Madrid.

Choy, E.

1962 Desarrollo del pensamiento especulativo en la sociedad esclavista de los incas. Actas y Trabajos. Segundo congreso nacional de Historia del Perú, tomo II:87-102, Lima.

Durkheim, E.

1893 De la Division du Travail Social. Félix Alcan, Paris.

1912 [1968] Las Formas Elementarias de la Vida Religiosa. Schapire, Buenos Aires.

Finley, M.

1973 The Ancient Economy. University of California Press, Berkeley y Los Angeles.

Firth, R.

1979 Work and value: Reflections on the ideas of Karl Marx. En Social Anthropology of Work, editado por S.Wallman, pp. 177-206. Academic Press, London y New York.

Garcilaso de la Vega

1943 [1609] Comentarios Reales de los Incas, editado por A. Rosenblat. Emecé Editores, Buenos Aires.

Godelier, M.

1973 Le concept de formation économique et sociale: l'exemple des Incas. En Horizon: Trajets Marxistes en Anthropologie, recopilado por M. Godelier, pp.179-87. Maspéro, Paris.

1980 Work and its representations: A research proposal. History Workshop Journal 10:164-174.

Goff, Le, J.

1980 Time, Work and Culture in the Middle Ages. Chicago University Press, Chicago.

Gose, P.

2001 Aguas Mortíferas y Cerros Hambrientos: Ritos Agrarios y Formación de Clase en un Pueblo Andino. Mama Huaco, La Paz.

Goudsmit, I.

2006 So Far from God so Near the Mountains: Peasant Deference to the State and Landlords in the Bolivian
Andes. $\mathrm{PhD}$ thesis in Anthropology, University of London, London.

Graeber, D.

2001 Toward an Anthropological Theory of Value. The False Coin of our Own Dreams. Palgrave, New York.

Guaman Poma de Ayala, F.

1987 [1615] Nueva Corónica y Buen Gobierno, editado por

J.V. Murra, R. Adorno y J. Urioste. Historia 16, Madrid.

Harris, O.

1987 El trabajo y el producto de una economía étnica en el norte de Potosí. En Economía Étnica, editado por O. Harris, pp. 5-62. HISBOL, La Paz.

2000 Condor and bull: the ambiguities of masculinity in Highland Bolivia. En To Make the Earth Bear Fruit. Ethnographic Essays on Fertility, Work and Gender in Highland Bolivia, editado por O. Harris. Institute of Latin American Studies, University of London, London.

Ingold, $\mathrm{T}$.

1983 The architect and the bee: Reflections on the work of animals and men. Man (N.S.) 18(1):1-20.

Lyons, B.

2006 Remembering the Hacienda: Religion, Authority, and Social Change in Highland Ecuador. University of Texas Press, Austin.

Marx, K.

1970 [1887] Capital. Vol.1. Lawrence and Wishart, London.

Matienzo, J. de

1967 [1567] Gobierno del Perú. Travaux de l'Institut Français des Études Andines, XI, Paris y Lima.

Mossé, C.

1969 The Ancient World at Work. Chatto and Windus, London.

Murra, J.V.

1978 [1956] La Organización Económica del Estado Inka. Instituto de Estudios Peruanos, Lima.

2004 [1966] Nueva información sobre las poblaciones yana. En El Mundo Andino: Población, Medio Ambiente y Economía, editado por J.V. Murra, pp. 328-341. Instituto de Estudios Peruanos, Lima.

Painter, M.

1991 Re-creating peasant economy in Southern Peru. En Golden Ages, Dark Ages. Imagining the Past in Anthropology and History, editado por J. O'Brien y W. Roseberry, pp. 81-106. University of California Press, Berkeley.

Passes, A.

2000 The value of working and speaking together: a facet of Pa'ikwené (Palikur) conviviality. En The Anthropology of Love and Anger: The Aesthetics of Conviviality in Native Amazonia, editado por J. Overing y A. Passes, pp. 97-113. Routledge, London.

Platt, T.

2001 El feto agresivo. Parto, formación de la persona y mitohistoria en los Andes. Anuario de Estudios Americanos 58(2):633-678.

Platt, T., T. Bouysse-Cassagne y O. Harris 2006 Qaraqara-Charka. Mallku, Inka y Rey en la Provincia de Charcas, Siglos XV-XVII. Plural Editores, La Paz.

Polo Ondegardo, J.

1990 [1571] Relación de los Fundamentos Acerca del Notable Daño que Resulta de no Guardar a los Indios sus Fueros, 
editado por L. González y A. Alonso. Crónicas de América 58, Historia 16, Madrid.

Ramírez del Águila, P. 1978 [1639] Noticias Políticas de Indias, editado por J. Urioste. Imprenta Universitaria, Sucre.

Sahlins, M.

1976 Economía de la Edad de Piedra. Akal Editor, Madrid.

Sánchez, R.

1982 The Andean economic system and capitalism. En Ecology and Exchange in the Andes, editado por D. Lehmann, pp. 157-190. Cambridge University Press, Cambridge.

Temple, D.

1989 Estructura Comunitaria y Reciprocidad: del quid-proquo Histórico al Economicidio. HISBOL-CHITAKOLLA, La Paz.

Thompson, E.P.

1989 La Formación de la Clase Obrera en Inglaterra. Editorial Crítica, Barcelona.
Urton, G.

1992 Communalism and differentiation in an Andean community. En Andean Cosmologies through Time: Persistence and Emergence, editado por R. Dover, K. Seibold y J. McDowell, pp. 229-266. Indiana University Press, Bloomington.

Vernant, J.P.

1965 Mythe et Pensée chez les Grecs II. Petite Collection Maspéro, Paris.

Wallman, S., editor

1979 Social Anthropology of Work. Academic Press, London y New York.

Yerushalmi, Y.H.

1982 Zakhor: Jewish History and Jewish Memory. University of Washington Press, Seattle.

Zuidema, R.T.

1989 El león en la ciudad. Símbolos reales de transición en el Cusco. En Reyes y Guerreros: Ensayos de Cultura Andina, compilado por M. Burga, pp. 306-383. FOMCIENCIAS, Lima.

\section{Notas}

1 He realizado trabajos de campo en el ayllu laymi en los años setenta, y en los ayllus de Sacaca en los ochenta. En lo que sigue, me refiero principalmente al período en que conocía bien a algunas comunidades rurales del norpotosino. Desde entonces muchas cosas han cambiado con respecto a las prácticas laborales, mientras que otras se mantienen iguales. Por tanto hablo a veces en tiempo presente.

2 Cabe subrayar que los extendidos debates sobre la reciprocidad andina giran en torno al intercambio del trabajo (p.ej., Alberti y Mayer 1974) y no el intercambio de objetos que predomina en la literatura global que trata de la reciprocidad y las teorías del don.

3 Algunos investigadores sobre las sociedades amazónicas han hecho hincapié en el placer de convivencia (conviviality) que se expresa mediante el trabajo en común (Passes 2000).

4 En otras regiones estos trabajos comunales se llaman ayni (p.ej., en el sur del Perú) o minga (en el norte de Ecuador, Colombia). En el norte de Potosí, como en general en el altiplano boliviano, no se habla tanto del ayni y la minga/ mink'a como en otras regiones andinas; ambas categorías refieren en el altiplano a intercambios de trabajo entre dos entes y no tanto a un trabajo propiamente colectivo.

5 Otro investigador que subraya la importancia de una ética de ayuda mutua en vez de los intercambios estrictos es Gose (2001).

6 El vocablo q'ara significa desnudo, o mal vestido; quizás se los tilda de esta manera porque a ellos les falta la 'piel social' de obligaciones y ayuda mutuas que según los laymi constituyen los verdaderos humanos. Vale apuntar que en las últimas décadas se ha producido un movimiento general del aymara al quechua como primer idioma en la región.

7 Cabe notar que en muchas regiones campesinas andinas ya no se encuentran -o solamente en forma muy reducidalos trabajos comunales, sobre todo en los valles donde son menos difíciles las condiciones para la agricultura.

8 Ver Graeber (2001:70) para un argumento parecido con respecto a Melanesia.
$9 \quad$ Estas respuestas específicas corresponden en particular al trabajo agrícola en la puna. Como ya lo hemos visto, en los valles las ricas comidas que se ofrecen durante el barbecho normalmente se preparan en común.

10 En la región cusqueña el castellano vivu se emplea con un significado parecido (Harvey comunicación personal 1998).

11 Sin embargo, parece que no existe una identificación semántica directa entre el arar y el parto tal como se encuentra en algunas lenguas europeas, por ejemplo el francés labour.

12 Cabe notar que el hilar y tejer tampoco se considera como ch'ama.

13 No es casual que dejo sin especificar de qué escala se trata al hablar de la comunidad. Depende del contexto, aunque en todo caso la base de comunidad son los derechos colectivos sobre la tierra.

14 Ninguno de estos escritores prestaba su atención a las labores femeninas.

15 Si bien Marx aprobaba la idea ilustrada de que los humanos realizan sus capacidades mediante la creatividad, el trabajo y la intencionalidad (Marx 1970 [1887]:178; Ingold 1983), ya en los Manuscritos de 1844 afirmaba que el sistema capitalista "restaba toda la creatividad y alegría que el trabajo pueda proporcionar" (ver Campbell 1989:20).

16 Este es el caso para la mayoría de los capítulos en la compilación sobre la antropología del trabajo, editada por Wallman (1979).

17 Vale reconocer que cuando Godelier retomó el tema del trabajo en sus investigaciones en años posteriores, privilegiaba una interpretación semántica, y en esta aproximación más relativista indicaba que él mismo reconocía los defectos de su propio argumento sobre los Inca (Godelier 1980).

18 Algunos investigadores han propuesto que se reconozca una diferenciación semántica entre varios aspectos del trabajo mediante los vocablos contrastados de 'trabajo' y 'labor' (p.ej., Arendt 1999; Firth 1979). Para mis propósitos esta solución no es tal, porque se vale de una definición universalista de lo que es el trabajo. 
